\title{
Investigations into the association between soil-transmitted helminth infections, haemoglobin and child development indices in Manufahi District, Timor-Leste
}

Suzy J. Campbell ${ }^{1 *}$, Susana V. Nery ${ }^{1}$, Catherine A. D’Este ${ }^{1}$, Darren J. Gray ${ }^{1,2,3}$, James S. McCarthy ${ }^{3,4}$, Rebecca J. Traub ${ }^{5}$, Ross M. Andrews ${ }^{6}$, Stacey Llewellyn ${ }^{4}$, Andrew J. Vallely ${ }^{7}$, Gail M. Williams ${ }^{3}$

and Archie C. A. Clements ${ }^{1}$

\begin{abstract}
Background: Timor-Leste has a high prevalence of soil-transmitted helminth (STH) infections. High proportions of the population have been reported as being anaemic, and extremely high proportions of children as stunted or wasted. There have been no published analyses of the contributions of STH to these morbidity outcomes in Timor-Leste.

Methods: Using baseline cross-sectional data from 24 communities (18 communities enrolled in a cluster randomised controlled trial, and identically-collected data from six additional communities), analyses of the association between STH infections and community haemoglobin and child development indices were undertaken. Stool samples were assessed for STH using GPCR and participant haemoglobin, heights and weights were measured. Questionnaires were administered to collect demographic and socioeconomic data. Intensity of infection was categorised using correlational analysis between qPCR quantification cycle values and eggs per gram of faeces equivalents, with algorithms generated from seeding experiments. Mixed-effects logistic and multinomial regression were used to assess the association between STH infection intensity classes and anaemia, and child stunting, wasting and underweight.

Results: Very high stunting (60\%), underweight (60\%), and wasting (20\%) in children, but low anaemia prevalence (15\%), were found in the study communities. STH were not significantly associated with morbidity outcomes. Male children and those in the poorest socioeconomic quintile were significantly more likely to be moderately and severely stunted. Male children were significantly more likely than female children to be severely underweight. Increasing age was also a risk factor for being underweight. Few risk factors emerged for wasting in these analyses.

Conclusions: According to World Health Organization international reference standards, levels of child morbidity in this population constitute a public health emergency, although the international reference standards need to be critically evaluated for their applicability in Timor-Leste. Strategies to improve child development and morbidity outcomes, for example via nutrition and iron supplementation programmes, are recommended for these communities. Despite the apparent lack of an association from STH in driving anaemia, stunting, wasting and underweight, high endemicity suggests a need for STH control strategies.
\end{abstract}

Trial registration: Australian and New Zealand Clinical Trials Registry ACTRN12614000680662; retrospectively registered. Keywords: Soil-transmitted helminths, Necator americanus, Ascaris, Morbidity, Anaemia, Stunting, Wasting, PCR

\footnotetext{
* Correspondence: suzanne.campbell@|stmed.ac.uk

${ }^{1}$ Research School of Population Health, College of Medicine, Biology and Environment, The Australian National University, 62 Mills Rd, Acton, ACT 2601, Australia

Full list of author information is available at the end of the article
} 


\section{Background}

Southeast Asia harbours one-third of the world's soiltransmitted helminths (STH) [1], and Timor-Leste is one of the poorest countries in the region [2]. Two recent cross-sectional studies identified moderate school-based (29\%) [3] and high community-based (69\%) [4] STH prevalence in the Manufahi District of Timor-Leste, using different diagnostic techniques. Specifically, in this area, prevalence of Necator americanus was $60 \%$, Ascaris spp. 24\%, Ancylostoma spp. 4.7\%, and Trichuris trichiura 0.33\%, with Giardia duodenalis the most common protozoan identified (13\%) [4]. Inadequate water and sanitation infrastructure and hygiene behaviours in this area likely contribute to high STH endemicity [4], which in turn could contribute significantly to morbidity.

STH have previously been associated with anaemia, stunting and wasting [5-9]. The mechanism whereby hookworms contribute to reduced haemoglobin and more indirectly to poor growth and development outcomes is via blood loss and inflammation, with heavily-infected people at greatest risk of morbidity [10]. Ascaris lumbricoides is not considered a contributor to blood loss (reviewed in [11]) and T. trichiura contributes to blood loss in heavy infection. Whilst STH have been shown to be associated with stunting and wasting $[12,13]$ the causal relationship is not clear.

Despite inability to establish causality with observational analyses, investigating the relationship between STH infection and haemoglobin concentration, and child anthropometric indices, is of considerable importance in Timor-Leste. Extremely high proportions of Timorese under 5 years of age are reported as stunted (50\%) and wasted (11\%) [14], yet knowledge of the contribution of STH to this is very limited, with no prior investigations identified. A cross-sectional survey in 2008 found $22 \%$ of children aged 24-59 months of age were anaemic [15]. Additionally, a demographic health survey in 2009-2010 found 38\% of Timorese children aged 6-59 months, and 21\% of Timorese women aged 15-49 years were anaemic [16]. Since this time, risk factors for anaemia in women of reproductive age have been investigated [17]. However, limited data on STH have prevented STH contributions from being assessed.

Using quantitative polymerase chain reaction (qPCR) for STH diagnosis and intensity of infection assessment [18], we aim to (i) determine classes of STH infection intensity from PCR-derived data, and (ii) provide the first analysis of morbidity associated with STH infections in Manufahi District, Timor-Leste. We used an algorithm to correlate quantification cycle $\left(\mathrm{C}_{\mathrm{q}}\right)$ values from $\mathrm{qPCR}$ to eggs per gram of faeces (epg) equivalents, determined by seeding experiments [18]. The association between intensity of $N$. americanus and Ascaris spp. (as exposures) and mean haemoglobin concentrations and anaemia diagnosis (as outcomes) were then investigated for all community members, and associations with stunting, underweight and low BMI-for-age (as a measure of wasting) as outcomes in children aged one to 18 years were also investigated.

\section{Methods}

\section{Study setting, design and collection of data}

This study was conducted as one of a series of baseline analyses for the "WASH for Worms" RCT, which aims to determine the extent of a reduction in burden of STH by integrating mass chemotherapy and communitybased water, sanitation and hygiene (WASH) programmes [19]. Rural communities in Manufahi District were selected for the study according to RCT-related inclusion and exclusion criteria (including being identified by the Timorese government as high-priority communities for WASH interventions) [19]. The RCT commenced in May 2012, with baseline surveys conducted in 18 communities until October 2013. Identically-collected data from six communities in Manufahi District were added; these communities were enrolled at the same time as the RCT communities but were not randomly allocated to each trial arm. Full details of study area and design [19], questionnaires and parasitological diagnostic approaches $[4,18]$ are provided elsewhere. Briefly, Manufahi District is comprised of rural Timorese villages with subsistence-based livelihoods. Community consultations and consent elicitation were conducted before questionnaire administration. Children aged less than 12 months and pregnant women in the first trimester of pregnancy were excluded because they could not receive albendazole. Questionnaires were used to record details of water, sanitation and hygiene (WASH) practices, household and individual socioeconomic characteristics [4].

\section{Measurement of anaemia status and anthropometry}

Anaemia status was measured for all ages with haemoglobin concentration assessed by finger-prick blood test using a portable haemoglobinometer (HemoCue, Ängelholm, Sweden). Haemoglobin concentrations can be used to assess anaemia (being inadequate intakes and reserves of host iron and protein [20]). Data on haemoglobin were linked to household GPS coordinates and adjusted by -2 grams per litre for elevation of $1000 \mathrm{~m}$ above sea level in accordance with World Health Organization (WHO) recommendations [21]; data from four communities, and part of a fifth community, were adjusted in this way; no communities had an elevation above $1500 \mathrm{~m}$. Haemoglobin was initially classified based on WHO definitions of anaemia severity (Table 1 [21]); however due to small numbers was re- 
Table 1 Definitions of anaemia used in this study, measured as grams per litre (source [23])

\begin{tabular}{lllll}
\hline & No anaemia & Mild anaemia & Moderate anaemia & Severe anaemia \\
\hline Children $<5$ years & $\geq 110$ & $100-109$ & $70-99$ & $<70$ \\
Children 5-11 years & $\geq 115$ & $110-114$ & $80-109$ & $<80$ \\
Children 12-14 years & $\geq 120$ & $110-119$ & $80-109$ & $<80$ \\
Non-pregnant women ( $\geq 15$ years) & $\geq 120$ & $110-119$ & $80-109$ & $<80$ \\
Pregnant women & $\geq 110$ & $100-109$ & $70-99$ & $<70$ \\
Men $(\geq 15$ years) & $\geq 130$ & $110-129$ & $80-109$ & $<80$ \\
\hline
\end{tabular}

categorised as a binary variable (anaemic/non-anaemic); which was used as the primary outcome.

For children aged two to $<18$ years, weight was measured to the nearest $0.1 \mathrm{~kg}$ using electronic scales (CAMRY, ED-301), and height was measured to the nearest $0.1 \mathrm{~cm}$ using a portable stadiometer (Wedderburn, WSHRP). Children aged 1 to 2 years had length measured supine with a measuring mat (Wedderburn, SE210), and weight measured by taring (i.e. with the child held by an adult, and the adult's weight subsequently deducted).

Height-for-age (HAZ) and BMI-for-age (BMIZ, i.e. weight over height ${ }^{2}$-for-age) $z$-scores were calculated for children aged $1-<18$ years. Weight-for-age (WAZ) $z$ scores were calculated for children aged $1-<10$ years, standardised to the international 2006 reference population using the software WHO Anthro and Anthroplus, for children up to five and aged five and over, respectively $[22,23]$. These scores are expressed as differences from the reference median and are calculated based on sex and date of birth of each individual. Age in days was used for z-score calculations. Children of uncertain birthdate were assigned a mid-year birthdate (15th June) and records followed up with parents subsequently; 1038 children's records (95.4\%) had completed birthdates. WAZ is only calculated up to 10 years of age, because it is considered inadequate for monitoring growth beyond this age [24]; BMIZ complements HAZ in the assessment of thinness (low BMIZ) [24], and was used instead of weight-for-height (which is calculated for under-fives only) to assess wasting. Each of these continuous outcomes was categorised, with individuals classified as moderately stunted, underweight or wasted if HAZ, WAZ and BMIZ respectively were more than two standard deviations below the reference median, and severely stunted, underweight or wasted, respectively, if the $z$-scores were more than three standard deviations below the reference median [25].

\section{Assessment of STH infection}

Single stool samples were collected, preserved in 5\% potassium dichromate at room temperature, transported to QIMR Berghofer Medical Research Institute, Brisbane, Australia, and tested by multiplex qPCR for presence and intensity of STH and protozoal infection using a method previously described [18]. Prevalence of all STH were assessed in this way. Based on highest prevalences, $N$. americanus and Ascaris spp. (reported at genus level) were analysed for intensity of infection. For purposes of this analysis, qPCR quantification cycle $\left(\mathrm{C}_{\mathrm{q}}\right)$ values, representing the amplification cycle where the signal exceeded background, was interpolated as a measure of the parasite DNA load in the stool sample [26], using a validated internal control. $\mathrm{C}_{\mathrm{q}}$-values were expressed on a $\log _{10}$ scale of the linear equation with fluorescence (i.e. $\log \left(b_{0}+b_{1} x\right)$ ), where the slope $\left(b_{1}\right)$ and the $y$-intercept $\left(b_{0}\right)$ are provided from the PCR output and $x$ is the $C_{\mathrm{q}}$-value. Lower values therefore denote heavier intensity infection. In these assays a $\mathrm{C}_{\mathrm{q}}$-value of 31 for Ascaris, and a $\mathrm{C}_{\mathrm{q}}$-value of 35 for $N$. americanus, were set as the limits for detection of infection [18]. All assays showed $\mathrm{C}_{\mathrm{q}}$-values for the internal control within the expected range.

\section{Data analysis}

Data were analysed in STATA 14.0 (Stata Corporation, College Station, Texas). A wealth quintile was constructed using principal components analysis of variables assessing ownership of household assets (including animals, transport and appliances), house floor type, reported income and presence of electricity as reported previously [4], according to established methods [27].

For faecal specimens, two runs were taken for each PCR assay. The arithmetic mean of the two (untransformed) $\mathrm{C}_{\mathrm{q}}$-values was taken to create a single measure per person. For ease of interpretation and for comparison with other studies, untransformed $\mathrm{C}_{\mathrm{q}}$ values were categorised in these analyses. Receiveroperating characteristic curves (ROCs) were used to assign initial cut-points for $\mathrm{C}_{\mathrm{q}}$-values, using a generated morbidity score (see Additional file 1). However, a very weak relationship between intensity of infection for either $N$. americanus or Ascaris and the morbidity score was observed (see below). This led to extremely poor predictive capacity using ROCs, so this technique was not ultimately used. Full detail of this is reported in Additional file 1, as statistical assignment of categories to infection intensities represent an important contribution that may be useful in 
assigning qPCR data to intensity of infection categories elsewhere.

An algorithm to assign intensity of infection based on approximations of epg was used for this analysis, with intensity classes being based on those endorsed by the WHO to represent high, moderate and low-intensity infections [28] (see Additional file 1 for detail). This algorithm was generated from seeding experiments as previously described [18] and was based on the linear relationship between the $\log _{10}$ of epg and $C_{\mathrm{q}}$-value [18]. Because WHO endorsed categorisations of epg intensity are based on the Kato-Katz diagnostic technique [28], a recovery factor of 0.2 was applied to current epg classes of infection intensity (based on a $20 \%$ recovery rate determined for faecal flotation of Ascaris eggs (R. Traub, unpublished data). This recovery factor was used in the absence of a recovery factor being known for Kato-Katz and the known poor accuracy of this technique in diagnosing STH infections [29]) (Table 2).

Using classes of infection intensity for epg based on international standards [28], the $\mathrm{C}_{\mathrm{q}}$ cut-point that correlated with heavy-intensity infection of $(\geq 4000 * 5=20,000)$ epg was selected for $N$. americanus, and the $\mathrm{C}_{\mathrm{q}}$ cut-point that correlated with heavy-intensity infection of ( $\geq 50,000 * 5=250,000$ ) epg was selected for Ascaris. The final intensity of infection variables for both STH were therefore categorised according to heavyintensity, moderate- to low-intensity (hereafter called "moderate-intensity"), and no infection, whereby moderate-intensity infection was all $\mathrm{C}_{\mathrm{q}}$ between the heavy-infection cut-point and the detectable $\mathrm{C}_{\mathrm{q}}$ limits of 31 for Ascaris, and 35 for N. americanus. Sensitivity analyses were then undertaken, comparing these cut-points to a model that applied a cut-point of $10 \%$ heavy-intensity infection (based on the percentage of endemic populations deemed by the WHO as likely to suffer morbidity from heavy infections [28]), a model of 15\% heavy-intensity infection, a model based on quintiles of infection intensity, and also comparing results from applying cut-points that have been reported elsewhere [30-32] to these data. The intensity cut-points

Table 2 Ascaris spp. and Necator americanus intensity of infection quantification cycle $\left(C_{q}\right)$ cut-points between heavy and moderate morbidity

\begin{tabular}{lllc}
\hline $\begin{array}{l}\text { Soil-transmitted } \\
\text { helminth }\end{array}$ & $\begin{array}{l}\text { Eggs per gram of } \\
\text { faeces (epg) class }\end{array}$ & $\begin{array}{l}\text { EPG class with } \\
\text { recovery factor } \\
\text { applied }^{b}\end{array}$ & $\begin{array}{l}\text { Corresponding } \\
\text { Cq-value }^{c}\end{array}$ \\
\hline N. americanus & $\geq 4000$ & 20,000 & 24.6 \\
Ascaris spp. & $\geq 50,000$ & 250,000 & 15.4 \\
\hline
\end{tabular}

Abbreviations: $C_{\mathrm{q}}$, quantification cycle; epg, eggs per gram of faeces

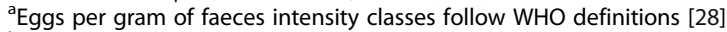

${ }^{b}$ Recovery factor of 0.2 applied to epg intensity class based on recovery factor determined from faecal flotation (R. Traub, unpublished data)

${ }^{c} \mathrm{DNA}$ intensity from exponentiated $\mathrm{C}_{\mathrm{q}}$-values selected using the WHO endorsed thresholds as estimated by the algorithm performed comparably to these other cut-points on sensitivity analyses based on parameter estimates and Akaike's Information Criteria, and thus were used in all further analyses.

Chi-square tests were conducted to compare prevalence of morbidity by age, sex and socioeconomic quintile; these variables were retained as core variables in all multivariable models. The associations between intensity of infection and morbidity by age group and sex were also explored. Mixed-effects logistic regression (for binary-coded anaemia as outcome) and mixed-effects multinomial regression within a generalised structural equation model framework (separately for outcomes of stunting, wasting and underweight) were undertaken to account for correlation among outcomes at the household and village level.

Initially univariable analyses were undertaken with each STH species, G. duodenalis, age group (categorical), sex as a binary variable, and socioeconomic quintile (categorical) included as explanatory variables for each of the morbidity outcomes. Although there was a high prevalence of $N$. americanus in this population [4], there was no multicollinearity with other STH species. Variables with $P<0.2$ from univariable analyses were added stepwise into a base model which included age group, sex, socioeconomic quintile, the categorical intensity of infection explanatory variables for $N$. americanus and Ascaris (described above), and binary Ancylostoma infection, until the most parsimonious adjusted model for each outcome was achieved. Variables were retained in final models if $P<0.1$ on the Wald test.

For models of stunting, underweight and wasting, anaemia was additionally included as a core variable because of its importance as a potential confounder. There were insufficient observations to investigate anaemia risk factors in children under five or within other childhood age groups. Anaemia was therefore modelled separately for children (aged $1-<18$ years) and adults, given the difference in prevalence and potential risk factors for these two groups. There were additionally insufficient observations to investigate stunting, wasting or underweight by age groups in regression analyses. Prevalence of both STH and morbidity vary with age and sex, and both the literature [33] and our earlier analyses [4] indicated the potential for moderation of the STHmorbidity relationship by age and sex. Given this, and observed differences in relationships between classes of $N$. americanus infection intensity and stunting across age and sex (identified in cross-tabulations), interactions between sex and $N$. americanus intensity of infection, and age group and $N$. americanus intensity of infection, were investigated. Interactions were investigated by generating models with and without the interaction term and comparing these using the likelihood ratio test, with 
a requirement for $P<0.1$ for likelihood ratio tests, for interaction inclusion in the model. Using these criteria, no interactions were required in adjusted models for anaemia. A sex by $N$. americanus intensity of infection interaction was retained in the adjusted child stunting model, and an age group by $N$. americanus intensity of infection interaction was retained in the adjusted child underweight model. For the multinomial child anthropometry models, sensitivity analyses using binary-coded prevalence of outcome (of main effects only, i.e. no interaction terms) were undertaken to investigate the impact of increasing power. Additionally, post-hoc calculations were performed to determine the power to detect effects within each outcome, adjusting for correlations within households and villages. These calculations indicated $80 \%$ power, with a $5 \%$ significance level, to detect odds ratios of 3.3 or more for anaemia outcomes, relative risks of 1.4 to 1.7 for stunting and underweight outcomes (depending on level of severity), and (reflecting lower numbers) relative risks of 2.1 to 9.5 for wasting as an outcome (according to level of severity).

\section{Results}

\section{Prevalence of morbidity}

Respondents from communities who provided both a stool and finger-prick blood sample were included in analyses of haemoglobin (2038 participants). Only 15\% of the population suffered from anaemia, with the majority of these (11\%) being only mildly anaemic, and only three children being severely anaemic (Tables 3 and 4). Anaemia was most prevalent in younger ages, and generally decreased with increasing age $(P<0.0001)$ (Fig. 1). The observed zero prevalence of anaemia in females aged 65 years and over is of interest, although

Table 3 Baseline characteristics of study participants $(N=2038)$

\begin{tabular}{|c|c|c|c|}
\hline \multirow[t]{2}{*}{$\begin{array}{l}\text { Baseline community } \\
\text { characteristics }\end{array}$} & $\begin{array}{l}\text { All ages } \\
(N=2038)\end{array}$ & $\begin{array}{l}\text { Children; aged } \\
1-<18 \text { years } \\
(N=1018)\end{array}$ & $\begin{array}{l}\text { Adults; aged } \\
\geq 18 \text { years } \\
(N=1020)\end{array}$ \\
\hline & $n(\%)$ & $n(\%)$ & $n(\%)$ \\
\hline $\begin{array}{l}\text { Mean haemoglobin } \\
(\mathrm{g} / \mathrm{L},(\mathrm{SD}))\end{array}$ & $131(16)^{a}$ & $126(13)^{a}$ & $136(16)^{a}$ \\
\hline Non-anaemic & $1731(85)$ & $872(86)$ & $859(84)$ \\
\hline Mildly anaemic & $222(11)$ & $95(9.3)$ & $127(13)$ \\
\hline $\begin{array}{l}\text { Moderately/severely } \\
\text { anaemic }^{\mathrm{b}}\end{array}$ & $86(4.2)$ & $51(5.0)$ & $33(3.3)$ \\
\hline Ascaris spp. prevalence & $501(25)$ & $302(30)$ & $199(20)$ \\
\hline N. americanus prevalence & $1238(61)$ & $522(51)$ & $716(70)$ \\
\hline Ancylostoma spp. prevalence & $99(4.9)$ & $44(4.3)$ & $55(5.4)$ \\
\hline G. duodenalis prevalence & $261(13)$ & $203(20)$ & $58(5.7)$ \\
\hline
\end{tabular}

Abbreviations: $g / /$ grams per litre; $S D$ standard deviation

${ }^{a}$ Mean and standard deviation presented instead of $n$ and \%

${ }^{\mathrm{b}}$ Moderate and severe anaemia categories combined to maintain

participant confidentiality participant numbers in older age groups were generally low. Adult women of reproductive age (aged 18-< 45 years) had higher prevalence of anaemia than men of the same age $(18.0$ vs $7.9 \%, P<0.0001)$. The overall prevalence of $N$. americanus and Ascaris were 61, and 24\%, respectively [4]. The prevalence of Ascaris was highest amongst children of preschool age, whereas $N$. americanus was most prevalent in adults (Table 3) [4].

Children $1-<18$ years old who provided stool and had height and/or weight measured were included in analyses of $z$-scores (Table 4). Extremely high levels of stunting (60\%), underweight (60\%), and wasting $(20 \%)$ were found, with $25 \%$ being severely stunted, $20 \%$ severely underweight, and $4.5 \%$ severely wasted (Table 4 ). This morbidity is reflected in the mean $z$-scores for each measure, all of which are well below zero. Stunting, underweight and wasting varied by age group with, generally, greater proportions of older children ( $\geq 10$ years) experiencing severe morbidity compared to younger age groups. The prevalence of stunting was significantly higher among poorer households compared to wealthier households $(P<0.0001)$ and among males compared to females $(P<0.0001)$, but the overall association between stunting and age was non-significant $(P=0.117)$. Exploratory analyses indicated some unexpected, but not statistically significant, trends. A greater proportion of uninfected males were severely stunted than $N$. americanus-infected males (Table 5). This trend did not exist for females, who instead showed greater proportions of uninfected having normal (i.e. nonstunted) growth. Similarly, children aged 1 to 5 years with $N$. americanus infection generally had lower prevalence of severe stunting; a trend that reversed in the oldest age group (where a lower proportion of severe stunting was seen in uninfected children (Table 5). These complex and varying underlying relationships confirmed our decision to investigate interaction terms using regression models.

Prevalence and severity of being underweight was moderately higher for males $(P=0.004)$, and generally increased by age $(P=0.002)$, but not socioeconomic quintile $(P=0.088)$. Prevalence and severity of wasting increased by age $(P<0.0001)$, but did not differ by sex $(P=0.651)$ or socioeconomic quintile $(P=0.666)$.

\section{Assignment of DNA intensity cut-points}

From PCR output, there were no $\mathrm{C}_{\mathrm{q}}$-values above 35 , indicating good reproducibility of the assays. There were very weak relationships between STH infection and all morbidity outcomes, which hampered statistical assignment of cut-points using ROC curves. Table 2 shows the final selected cut-points. Using our cut-points, 1155 (52\%) of study subjects were categorised as having heavy-intensity $N$. americanus 
Table 4 Anthropometric characteristics of study participants $(N=2038)$

\begin{tabular}{|c|c|c|c|c|}
\hline \multicolumn{5}{|l|}{ Z-score characteristics } \\
\hline Height-for-age (HAZ) ${ }^{a}$ & $\begin{array}{l}\text { All children } 1-<18 \text { years }(N=983) \\
n(\%)\end{array}$ & $\begin{array}{l}1-<5 \text { years }(N=267) \\
n(\%)\end{array}$ & $\begin{array}{l}5-<10 \text { years }(N=365) \\
n(\%)\end{array}$ & $\begin{array}{l}\geq 10 \text { years }(N=351) \\
n(\%)\end{array}$ \\
\hline Mean HAZ (SD) ${ }^{a}$ & $-2.25(1.22)^{a}$ & & & \\
\hline Not stunted & $391(40)$ & $105(39)$ & $164(45)$ & $122(35)$ \\
\hline Moderately stunted & 347 (35) & $89(33)$ & $132(36)$ & $126(36)$ \\
\hline Severely stunted & $245(25)$ & $73(27)$ & $69(19)$ & $103(29)$ \\
\hline Weight-for-age (WAZ) ${ }^{\mathrm{b}}$ & $\begin{array}{l}\text { All children } 1-<10 \text { years }(N=639) \\
\mathrm{n}(\%)\end{array}$ & $\begin{array}{l}1-<5 \text { years } \\
(N=268) \\
n(\%)\end{array}$ & $\begin{array}{l}5-<10 \text { years }(N=371) \\
\mathrm{n}(\%)\end{array}$ & \\
\hline Mean WAZ (SD) ${ }^{b}$ & $-2.19(1.03)^{\mathrm{a}}$ & & & \\
\hline Not underweight & $257(40)$ & $124(46)$ & $133(36)$ & \\
\hline Moderately underweight & $253(40)$ & $108(40)$ & $145(39)$ & \\
\hline Severely underweight & $129(20)$ & $36(13)$ & $93(25)$ & \\
\hline BMI-for-age (BMIZ) ${ }^{a}$ & $\begin{array}{l}\text { All children } 1-<18 \text { years }(N=985) \\
n(\%)\end{array}$ & $\begin{array}{l}1-<5 \text { years }(N=266) \\
n(\%)\end{array}$ & $\begin{array}{l}5-<10 \text { years }(N=369) \\
n(\%)\end{array}$ & $\begin{array}{l}\geq 10 \text { years }(N=350) \\
n(\%)\end{array}$ \\
\hline Mean BMIZ (SD) ${ }^{\mathrm{a}}$ & $-1.19(1.03)^{\mathrm{a}}$ & & & \\
\hline Not wasted & $796(81)$ & $242(91)$ & $308(84)$ & $246(70)$ \\
\hline Moderately wasted & $145(15)$ & $20(7.5)$ & $47(13)$ & $78(22)$ \\
\hline Severely wasted & $44(4.5)$ & $4(1.5)$ & $14(3.8)$ & $26(7.4)$ \\
\hline
\end{tabular}

Abbreviations: HAZ height-for-age, WAZ weight-for-age, BMIZ BMI-for-age, SD standard deviation

${ }^{a} \mathrm{HAZ}$ (stunting) and BMI (wasting) calculated for individuals 12 months to $<18$ years of age

${ }^{b}$ WAZ (as indicator of underweight) only calculated for individuals 12 months to 10 years of age

infection, and 191 (8.6\%) moderate-intensity infection (Table 6). For Ascaris, 220 (9.9\%) people had heavyintensity infection, and $318(14 \%)$ people moderateintensity infection. Amongst infected people, $N$. americanus mean infection intensity was $C_{q} 21.5$ (95\% confidence interval, CI: 21.3-21.8), and for Ascaris 19.5 (95\% CI: 19.2-19.9) (Table 6). Intensity of infection changed over age, with most heavy-intensity Ascaris infection occurring in young children. Heavyintensity $N$. americanus infections were more evenly distributed across age groups, including older age groups.

\section{Factors associated with anaemia}

Neither Ascaris nor $N$. americanus infection intensity were significantly associated with anaemia in the multivariable models, although Ascaris moderate-intensity infection was marginally non-significant as a risk factor for adults (Table 7). Heavy N. americanus infection in children had a protective association with anaemia. However, this was not a significant factor in adjusted models, potentially indicating the confounding effect of other model factors. Increasing age was a highly significant, strongly protective factor in univariable and adjusted models for

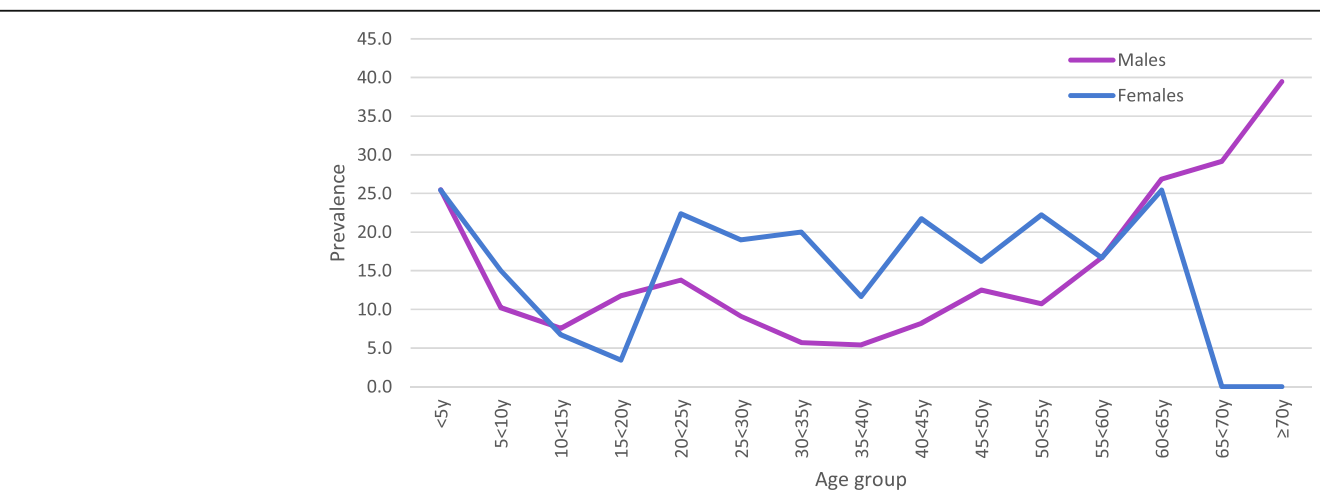

Fig. 1 Anaemia distribution by sex and age group $(n=2000)$ 
Table 5 Baseline characteristics of children by category of stunting $(N=592)$

\begin{tabular}{|c|c|c|c|}
\hline $\begin{array}{l}\text { Baseline community } \\
\text { characteristics }\end{array}$ & $\begin{array}{l}\text { Not } \\
\text { stunted } \\
n(\%)\end{array}$ & $\begin{array}{l}\text { Moderately } \\
\text { stunted } \\
n(\%)\end{array}$ & $\begin{array}{l}\text { Severely } \\
\text { stunted } \\
n(\%)\end{array}$ \\
\hline \multicolumn{4}{|l|}{ Males } \\
\hline $\begin{array}{l}\text { High N. americanus } \\
\text { infection intensity }\end{array}$ & $92(36)$ & $96(37)$ & $70(27)$ \\
\hline $\begin{array}{l}\text { Moderate } N \text {. americanus } \\
\text { infection intensity }\end{array}$ & $10(31)$ & $10(31)$ & $12(38)$ \\
\hline No N. americanus infection & $57(27)$ & $80(38)$ & $76(36)$ \\
\hline Total & $159(32)$ & $186(37)$ & $158(31)$ \\
\hline \multicolumn{4}{|l|}{ Females } \\
\hline $\begin{array}{l}\text { High N. americanus } \\
\text { infection intensity }\end{array}$ & $80(48)$ & $54(32)$ & $35(21)$ \\
\hline $\begin{array}{l}\text { Moderate } N \text {. americanus } \\
\text { infection intensity }\end{array}$ & $16(39)$ & $17(41)$ & $8(20)$ \\
\hline No N. americanus infection & $136(50)$ & $90(33)$ & $44(16)$ \\
\hline Total & $232(48)$ & $161(34)$ & $87(18)$ \\
\hline \multicolumn{4}{|l|}{ Age group 1 to 5 years } \\
\hline $\begin{array}{l}\text { High } N \text {. americanus } \\
\text { infection intensity }\end{array}$ & $38(48)$ & $27(34)$ & $14(18)$ \\
\hline $\begin{array}{l}\text { Moderate } N \text {. americanus } \\
\text { infection intensity }\end{array}$ & $12(43)$ & $11(39)$ & $5(18)$ \\
\hline No N. americanus infection & $89(38)$ & $79(34)$ & $65(28)$ \\
\hline Total & $139(41)$ & $117(34)$ & $84(25)$ \\
\hline \multicolumn{4}{|l|}{ Age group 6 to 11 years } \\
\hline $\begin{array}{l}\text { High N. americanus } \\
\text { infection intensity }\end{array}$ & $94(43)$ & $79(36)$ & $47(21)$ \\
\hline $\begin{array}{l}\text { Moderate } N \text {. americanus } \\
\text { infection intensity }\end{array}$ & $10(35)$ & $11(38)$ & $8(28)$ \\
\hline No N. americanus infection & $78(43)$ & $62(34)$ & $41(23)$ \\
\hline Total & $182(42)$ & $152(35)$ & $96(22)$ \\
\hline \multicolumn{4}{|l|}{ Age group 12 to 17 years } \\
\hline $\begin{array}{l}\text { High N. americanus } \\
\text { infection intensity }\end{array}$ & $40(31)$ & $44(34)$ & $44(34)$ \\
\hline $\begin{array}{l}\text { Moderate } N \text {. americanus } \\
\text { infection intensity }\end{array}$ & $4(25)$ & $5(31)$ & $7(44)$ \\
\hline No N. americanus infection & $26(38)$ & $29(42)$ & $14(20)$ \\
\hline Total & 70 (33) & 78 (37) & 65 (31) \\
\hline
\end{tabular}

children. There was no sex difference in odds of anaemia in children. Children in the poorest socioeconomic quintile had twice the odds of anaemia relative to those in the wealthiest quintile. For adults, age was non-significant, and neither sex nor socioeconomic status were associated with anaemia, with no evidence of an overall trend in odds with decreasing socioeconomic quintile.

\section{Factors associated with stunting}

No level of either $N$. americanus or Ascaris infection intensity was associated with stunting of any severity in this population (Table 8). However, whilst not statistically significant, heavy-intensity Ascaris infection was associated with higher relative risks for both moderate and severe stunting; these relative risks were of reasonable size (moderate stunting adjusted relative risk (ARR) 1.6, 95\% CI: 0.87-2.9; severe stunting ARR 2.0, 95\% CI: 0.87-4.4). Sensitivity analysis of stunting prevalence showed that heavyintensity Ascaris infection was marginally nonsignificantly associated with greater odds of stunting compared to uninfected children (adjusted odds ratio (AOR) 1.8, 95\% CI: 0.98-3.4, $P=0.057$; results not shown). In the multinomial stunting model (Table 8), Ancylostoma infection was associated with moderate and severe stunting. However, the effect was in the opposite direction to anticipated: children with $A n c y$ lostoma infection were significantly less likely to have moderate or severe stunting than uninfected children.

Due to inclusion of a sex by $N$. americanus interaction term, we report results of the association between $N$. americanus and stunting separately for males and females. Females with $N$. americanus infection of any intensity had no significant association with stunting of any severity. Being male and having heavy-intensity $N$. americanus infection (relative to being male and having no $N$. americanus infection) was associated with significantly reduced risk of severe stunting. It is important to note, however, that the main effect of $N$. americanus infection intensity showed that there was no association with stunting in females (the reference category). The main effect for sex indicates that, in those with no $N$. americanus infection, being male was highly significantly associated with almost three times the risk of moderate stunting,

Table 6 Necator americanus and Ascaris spp. intensity of infection profile. Numbers indicate all those who provided a stool sample, and therefore are not consistent with the numbers used in separate morbidity analyses

\begin{tabular}{llllll}
\hline STH & \multicolumn{2}{l}{ Infection intensity profile $n(\%)$} & & Mean C $(95 \%$ Cl) \\
\cline { 2 - 5 } & Heavy intensity & Moderate to low intensity & No infection & 21.5 (21.3-21.8) \\
\hline N. americanus & $1155(52.0)$ & $191(8.6)$ & $873(39.0)$ & $1689(76.0)$ & $19.5(19.2-19.9)$ \\
Ascaris spp. & $220(9.9)$ & $310(14.0)$ & 1689 & \\
\hline
\end{tabular}


Table 7 Odds ratios for anaemia, by Necator americanus and Ascaris spp. infection intensity, Manufahi District, Timor-Leste. Logistic regression was used for investigating factors associated with anaemia. The outcome variable is binomial anaemic/non-anaemic and associations therefore presented as odds ratios

\begin{tabular}{|c|c|c|c|c|c|c|c|c|c|c|}
\hline \multirow[b]{3}{*}{ Parameter } & \multicolumn{5}{|c|}{ Children; aged $1<18$ years $(N=1018)$} & \multicolumn{5}{|c|}{ Adults; aged $\geq 18$ years $(N=1020)$} \\
\hline & \multicolumn{2}{|c|}{ Univariable } & \multicolumn{3}{|c|}{ Multivariable } & \multicolumn{2}{|c|}{ Univariable } & \multicolumn{3}{|c|}{ Multivariable } \\
\hline & $\mathrm{OR}$ & $95 \% \mathrm{Cl}$ & AOR & $95 \% \mathrm{Cl}$ & $P$ & $\mathrm{OR}$ & $95 \% \mathrm{Cl}$ & $\mathrm{AOR}$ & $95 \% \mathrm{Cl}$ & $P$ \\
\hline Ascaris heavy-intensity & 0.93 & $0.49-1.8$ & 0.91 & $0.46-1.8$ & 0.8820 & 1.7 & $0.84-3.3$ & 1.8 & $0.86-3.6$ & 0.1165 \\
\hline Ascaris moderate-intensity & 0.73 & $0.39-1.4$ & 0.85 & $0.44-1.6$ & & $1.7^{* *}$ & $1.04-2.9$ & 1.6 & $0.93-2.7$ & \\
\hline N. americanus heavy-intensity & $0.52^{* * *}$ & $0.33-0.83$ & 0.69 & $0.41-1.1$ & 0.1606 & 0.92 & $0.62-1.4$ & 0.86 & $0.56-1.3$ & 0.7280 \\
\hline N. americanus moderate-intensity & $0.42^{\mathrm{a}}$ & $0.18-1.0$ & $0.50^{\mathrm{a}}$ & $0.21-1.2$ & & 0.99 & $0.52-1.9$ & 1.0 & $0.52-1.9$ & \\
\hline Ancylostoma infection & $1.5^{\mathrm{a}}$ & $0.58-3.9$ & $1.5^{\mathrm{a}}$ & $0.58-4.1$ & 0.3940 & $0.93^{\mathrm{a}}$ & $0.42-2.1$ & $0.68^{\mathrm{a}}$ & $0.27-1.7$ & 0.4130 \\
\hline G. duodenalis infection & 0.92 & $0.56-1.5$ & & & & $0.42^{\mathrm{a}}$ & $0.16-1.1$ & & & \\
\hline Male sex & 1.1 & $0.70-1.6$ & 0.97 & $0.64-1.5$ & 0.8940 & 0.93 & $0.66-1.3$ & 0.98 & $0.68-1.4$ & 0.9180 \\
\hline Age group 6 to 11 years & $0.35^{* * *}$ & $0.22-0.54$ & 0.39 & $0.24-0.61$ & $<0.0001$ & & & & & \\
\hline Age group 12 to 17 years & $0.20^{* * *}$ & $0.11-0.38$ & 0.19 & $0.09-0.38$ & $<0.0001$ & & & & & \\
\hline Age group $65+$ years & & & & & & 1.2 & $0.74-1.9$ & 1.2 & $0.76-2.0$ & 0.3920 \\
\hline Socioeconomic quintile 4 & 1.0 & $0.49-2.0$ & 0.93 & $0.46-1.9$ & 0.0098 & 0.58 & $0.31-1.1$ & 0.58 & $0.31-1.1$ & 0.3718 \\
\hline Socioeconomic quintile 3 & 0.52 & $0.23-1.2$ & 0.49 & $0.22-1.1$ & & 0.85 & $0.48-1.5$ & 0.83 & $0.46-1.5$ & \\
\hline Socioeconomic quintile 2 & 1.2 & $0.60-2.4$ & 1.1 & $0.55-2.2$ & & 1.1 & $0.65-2.0$ & 1.1 & $0.62-1.9$ & \\
\hline Socioeconomic quintile 1 (poorest) & $2.1^{* *}$ & $1.0-4.1$ & 2.1 & $1.0-4.3$ & & 0.97 & $0.54-1.7$ & 0.91 & $0.50-1.7$ & \\
\hline
\end{tabular}

Notes: Ascaris (categorical infection intensity), N. americanus (categorical infection intensity), Ancylostoma infection prevalence (binary), age group, sex and socioeconomic quintile were included in all multivariable regression models as exposure outcomes and covariates. Reference categories: no Ascaris infection, no $N$. americanus infection, no Ancylostoma infection, no Giardia infection, age group 1-5 years (for child model), age group 18-64 years (for adult model), male sex, socioeconomic quintile 5 (wealthiest) Abbreviations: $O R$ odds ratio, $A O R$ adjusted odds ratio, $C l$ confidence interval; $P$, Wald test $P$-value

${ }^{* *} P<0.05,{ }^{* * *} P<0.01$ in univariable analysis

a Less than 10 observations in a subgroup; result should be interpreted cautiously

Ascaris and N. americanus intensity infections were defined according to following cut-points: Ascaris: heavy-intensity $C_{q} \leq 15.4$, moderate-intensity $C_{q}>15.4<31$, no infection $C_{q} \geq 31 ; N$. americanus: heavy-intensity $C_{q} \leq 24.6$, moderate-intensity $C_{q}>24.6<35$, no infection $C_{q} \geq 35$

and almost seven times the risk of severe stunting. Relative to children aged one to five, children aged 12 to 17 had almost twice the risk of moderate stunting, and almost three times the risk of severe stunting, although no significant associations were seen in children aged 6 to 11 years. Children in the poorest socioeconomic quintile had twice the risk of moderate stunting, and five times the risk of severe stunting, compared to children in the wealthiest socioeconomic quintile. Anaemia was not a risk factor for stunting.

\section{Factors associated with being underweight}

The association between underweight and N. americanus infection is reported separately by age group because of the age group by $N$. americanus interaction term. In those aged one to five, $N$. americanus infection of any severity was not associated with being underweight. Whilst this same association was evident for children aged six to ten with $N$. americanus infection, the association with being severely underweight was only marginally non-significant for those having moderate $N$. americanus intensity of infection. Compared to children aged 1 to 5 years, being aged 6 to 10 years was significantly associated with three times the risk of being severely underweight, but no increased risk of being moderately underweight, in $N$. americanus-uninfected children. There was no association between intensity of Ascaris infection and being underweight in this population (Table 9). Ancylostoma infection was close to significance for being moderately underweight, but not for being severely underweight. The presence of $G$. duodenalis infection, or of anaemia, were also not significantly associated with being underweight. Being male was highly significantly associated with three times greater risk of being severely underweight compared to normal growth children, but this association was not evident for moderate levels of underweight. Household socioeconomic quintile was not associated with being underweight in these analyses, although the association with poorest socioeconomic quintile was only marginally not significant for being moderately underweight. With binary-coded underweight as outcome, a sensitivity analysis confirmed the consistency of results with the multinomial results.

\section{Factors associated with wasting}

Although no intestinal parasites were associated with wasting in adjusted analyses, observation numbers in this model were very low for assessment of some categories (Table 10). Additionally, the presence of 
Table 8 Relative risk ratios for stunting, Manufahi District, Timor-Leste

\begin{tabular}{|c|c|c|c|c|c|c|c|c|c|c|}
\hline \multirow[b]{2}{*}{ Parameter } & \multicolumn{5}{|c|}{ Moderate stunting $(n=347)$} & \multicolumn{5}{|c|}{ Severe stunting $(n=245)$} \\
\hline & $\mathrm{RR}$ & $95 \% \mathrm{Cl}$ & ARR & $95 \% \mathrm{Cl}$ & $P$ & $\mathrm{RR}$ & $95 \% \mathrm{Cl}$ & ARR & $95 \% \mathrm{Cl}$ & $P$ \\
\hline Ascaris heavy-intensity & 1.5 & $0.83-2.7$ & 1.6 & $0.87-2.9$ & 0.3007 & 1.8 & $0.79-4.0$ & 2.0 & $0.87-4.4$ & 0.2002 \\
\hline Ascaris moderate-intensity & 1.1 & $0.65-1.8$ & 1.0 & $0.61-1.7$ & & 1.0 & $0.50-2.0$ & 0.93 & $0.46-1.9$ & \\
\hline N. americanus heavy-intensity ${ }^{a}$ & 0.82 & $0.56-1.2$ & 0.82 & $0.47-1.4$ & 0.6140 & 0.73 & $0.43-1.2$ & 0.91 & $0.41-2.0$ & 0.8647 \\
\hline N. americanus moderate-intensity ${ }^{a}$ & 0.86 & $0.42-1.7$ & 1.3 & $0.52-3.1$ & & 0.67 & $0.27-1.7$ & 0.70 & $0.18-2.7$ & \\
\hline Male sex ${ }^{b}$ & $2.0^{* * *}$ & $1.4-2.8$ & 2.8 & $1.7-4.7$ & $<0.0001$ & $3.7^{* * *}$ & $2.3-6.0$ & 6.8 & $3.4-13.7$ & $<0.0001$ \\
\hline $\begin{array}{l}\text { N. americanus heavy-intensity } \\
\text { infection in males }{ }^{c}\end{array}$ & & & 0.65 & $0.31-1.4$ & 0.2540 & & & 0.31 & $0.11-0.85$ & 0.0230 \\
\hline $\begin{array}{l}\text { N. americanus moderate-intensity } \\
\text { infection in males }{ }^{c}\end{array}$ & & & 0.43 & $0.10-1.8$ & 0.2440 & & & 0.82 & $0.13-5.3$ & 0.8340 \\
\hline Ancylostoma infection & $0.26^{* * * d}$ & $0.11-0.65$ & $0.27^{d}$ & $0.11-0.68$ & 0.0050 & $0.33^{* * d}$ & $0.11-0.99$ & $0.37^{d}$ & $0.12-1.1$ & 0.0780 \\
\hline Giardia infection & 1.5 & $0.96-2.3$ & & & & 1.1 & $0.61-2.0$ & & & \\
\hline Anaemia prevalence & 1.2 & $0.68-2.0$ & 1.1 & $0.65-2.0$ & 0.6600 & 1.7 & $0.86-3.3$ & 1.7 & $0.83-3.4$ & 0.1470 \\
\hline Age group 6 to 11 years & 0.92 & $0.63-1.4$ & 1.1 & $0.71-1.6$ & 0.7090 & 0.72 & $0.43-1.2$ & 1.1 & $0.60-1.9$ & 0.8620 \\
\hline Age group 12 to 17 years & 1.4 & $0.86-2.3$ & 1.7 & $0.98-2.8$ & 0.0580 & 1.7 & $0.87-3.2$ & 2.7 & $1.3-5.4$ & 0.0060 \\
\hline Socioeconomic quintile 4 & 1.1 & $0.59-2.1$ & 1.2 & $0.63-2.2$ & 0.2415 & 0.91 & $0.34-2.5$ & 1.1 & $0.39-2.9$ & 0.0165 \\
\hline Socioeconomic quintile 3 & 1.4 & $0.69-2.7$ & 1.4 & $0.70-2.8$ & & 1.2 & $0.41-3.4$ & 1.3 & $0.45-3.8$ & \\
\hline Socioeconomic quintile 2 & 1.3 & $0.65-2.4$ & 1.2 & $0.64-2.3$ & & 1.5 & $0.55-4.0$ & 1.5 & $0.57-4.2$ & \\
\hline Socioeconomic quintile 1 (poorest) & $2.3^{* *}$ & $1.1-4.6$ & 2.3 & $1.1-4.6$ & & $5.1^{* * *}$ & $1.8-14.2$ & 5.1 & $1.8-14.7$ & \\
\hline
\end{tabular}

Notes: RRs in bold had univariable $P<0.2$ and were entered in multivariable regression models; for correct interpretation of this table, if a variable was significant for moderate stunting but not severe stunting, it was still included, therefore on occasion moderate stunting adjusted RRs are significant when severe stunting adjusted RRs are not, and vice versa. Ascaris (categorical infection intensity), N. americanus (categorical infection intensity), Ancylostoma infection prevalence (binary), anaemia prevalence (binary), age group, sex and socioeconomic quintile were included in all multivariable regression models as exposure outcomes and covariates. A sex* $N$. americanus interaction is included in the model. Reference categories: no Ascaris infection, no N. americanus infection, female sex, no N. americanus infection in males (multivariable only), no Ancylostoma infection, no Giardia infection, no anaemia, age group 1-5 years, socioeconomic quintile 5 (wealthiest)

Abbreviations: $R R$ relative risk, $A R R$ adjusted relative risk, $C l$ confidence interval; $P$, Wald test $P$-value

${ }^{* *} P<0.05,{ }^{* * *} P<0.01$ in univariable analysis

${ }^{a}$ The $N$. americanus main effect, being $N$. americanus infection intensity relative to no $N$. americanus infection in females (because females are the reference group)

${ }^{\mathrm{b}}$ The male sex main effect, being the relative risk of male sex relative to female sex when there is no $N$. americanus infection (reference group)

${ }^{c} N$. americanus infection intensity in males is relative to no $N$. americanus infection in males (because males and moderate- or heavy-intensity $N$. americanus infection are not the reference groups)

${ }^{\mathrm{d}}$ Ten observations or less in subgroup; result should be interpreted cautiously

Normal growth (no stunting) is reference category, i.e. moderate and severe stunting need to be interpreted relative to this reference. Ascaris and $N$. americanus intensity infections defined according to following cut-points: Ascaris: heavy-intensity $C_{q} \leq 15.4$, moderate-intensity $C_{q}>15.4<31$, no infection $C_{q} \geq 31 ; N$. americanus: heavy-intensity $C_{q} \leq 24.6$, moderate-intensity $C_{q}>24.6<35$, no infection $C_{q} \geq 35$

anaemia was not associated with wasting. Relative to being aged 1 to 5 years, being aged 6 to 11 years was associated with highly significant, threefold increased risk for being either moderately or severely wasted. Strikingly, this trend worsened amongst children aged 12 to 17 years, with four times the risk of moderate wasting, and seven times the risk of severe wasting, seen in these children relative to the youngest age group. There was no association between sex or socioeconomic status and categories of wasting. Given low numbers with this multinomial wasting outcome, a sensitivity analysis was conducted using wasting as a binary-coded outcome; results were consistent with the multinomial analyses, with age group the sole significant factor.

\section{Discussion}

In this first investigation of STH associations with haemoglobin and child development indices in Manufahi
District, Timor-Leste, a generally lower prevalence of anaemia than results reported previously [17] was observed, with $11 \%$ prevalence in children aged $1-<5$ years, and $18 \%$ prevalence in reproductive-aged women (18$<45$ years of age). For women, anaemia whilst moderately lower than reported previously [17], was significantly more frequent than in males of the same age, confirming the serious disease burden in this population group. This likely reflects the well-reported impact of pregnancies and menstruation on iron stores [34]. Anaemia in mothers is itself a risk factor for stunting or wasting in offspring. Iron-folic acid supplementation for pregnant women has been implemented by the Ministry of Health across all districts of Timor-Leste since 2003, with $61 \%$ of pregnant women reporting taking supplements in 2009-2010 [16].

Despite the difference in prevalence, being female was not demonstrated to be a risk factor for anaemia in 
Table 9 Relative risk ratios for being underweight, Manufahi District, Timor-Leste

\begin{tabular}{|c|c|c|c|c|c|c|c|c|c|c|}
\hline \multirow[b]{2}{*}{ Parameter } & \multicolumn{5}{|c|}{ Moderate underweight $(n=253)$} & \multicolumn{5}{|c|}{ Severe underweight $(n=129)$} \\
\hline & $\mathrm{RR}$ & $95 \% \mathrm{Cl}$ & ARR & $95 \% \mathrm{Cl}$ & $P$ & $\mathrm{RR}$ & $95 \% \mathrm{Cl}$ & ARR & $95 \% \mathrm{Cl}$ & $P$ \\
\hline Ascaris heavy-intensity & 1.0 & $0.53-2.1$ & 0.85 & $0.41-1.7$ & 0.8925 & 1.6 & $0.72-3.5$ & 1.2 & $0.49-2.8$ & 0.9379 \\
\hline Ascaris moderate-intensity & 1.1 & $0.60-2.1$ & 1.0 & $0.52-1.9$ & & 1.5 & $0.73-3.3$ & 1.0 & $0.46-2.3$ & \\
\hline N. americanus heavy-intensity ${ }^{a}$ & 1.0 & $0.64-1.7$ & 0.59 & $0.28-1.2$ & 0.3584 & 0.85 & $0.47-1.5$ & 0.66 & $0.25-1.8$ & 0.1519 \\
\hline N. americanus moderate-intensity ${ }^{a}$ & 0.94 & $0.41-2.2$ & 0.76 & $0.26-2.2$ & & $0.87^{d}$ & $0.31-2.5$ & $0.12^{d}$ & $0.01-1.2$ & \\
\hline Age group 6 to 10 years $^{b}$ & 1.4 & $0.91-2.2$ & 1.2 & $0.63-2.2$ & 0.5930 & $2.8^{* * *}$ & $1.6-4.8$ & 3.3 & $1.5-7.0$ & 0.0030 \\
\hline $\begin{array}{l}\text { Age group } 6 \text { to } 10 \text { years and } N \text {. } \\
\text { americanus heavy-intensity infection }\end{array}$ & 1.4 & $0.80-2.5$ & 1.8 & $0.67-4.8$ & 0.2510 & 1.7 & $0.81-3.6$ & 0.70 & $0.20-2.4$ & 0.5740 \\
\hline $\begin{array}{l}\text { Age group } 6 \text { to } 10 \text { years and } N \text {. } \\
\text { americanus moderate-intensity infection }\end{array}$ & 1.8 & $0.39-8.2$ & 2.1 & $0.30-13.9$ & 0.4630 & 7.0 & $1.36-35.8$ & 15.6 & $0.91-266.4$ & 0.0580 \\
\hline Ancylostoma infection & 2.5 & $0.88-6.8$ & 2.8 & $0.94-8.1$ & 0.0640 & $0.69^{d}$ & $0.15-3.2$ & $0.86^{\mathrm{d}}$ & $0.18-4.2$ & 0.8480 \\
\hline Giardia infection & 0.97 & $0.58-1.6$ & & & & 1.1 & $0.58-2.1$ & & & \\
\hline Anaemia prevalence & 0.99 & $0.56-1.8$ & 0.98 & $0.54-1.8$ & 0.9430 & 0.70 & $0.34-1.5$ & 0.85 & $0.39-1.9$ & 0.6820 \\
\hline Male sex & 1.3 & $0.85-2.0$ & 1.3 & $0.81-2.0$ & 0.3040 & $2.4^{* * *}$ & $1.4-4.2$ & 3.1 & $1.7-5.6$ & $<0.0001$ \\
\hline Socioeconomic quintile 4 & 1.4 & $0.66-3.1$ & 1.5 & $0.66-3.3$ & 0.2606 & 0.57 & $0.20-1.6$ & 0.66 & $0.23-1.9$ & 0.3095 \\
\hline Socioeconomic quintile 3 & 1.1 & $0.46-2.4$ & 1.1 & $0.48-2.6$ & & 1.0 & $0.36-2.8$ & 1.1 & $0.37-3.0$ & \\
\hline Socioeconomic quintile 2 & 1.1 & $0.53-2.5$ & 1.2 & $0.54-2.7$ & & 0.87 & $0.33-2.3$ & 0.96 & $0.36-2.6$ & \\
\hline Socioeconomic quintile 1 (poorest) & 2.4 & $1.0-5.6$ & 2.5 & $1.0-6.1$ & & 2.0 & $0.72-5.8$ & 2.2 & $0.76-6.6$ & \\
\hline
\end{tabular}

Notes: Ascaris (categorical infection intensity), N. americanus (categorical infection intensity), Ancylostoma infection prevalence (binary), anaemia prevalence (binary), age group, sex and socioeconomic quintile were included in all multivariable regression models as exposure outcomes and covariates. Being underweight not measured in children aged 11 to 17 years. An age group*N. americanus interaction is included in the model. Reference categories: No Ascaris infection, no N. americanus infection, age group 1-5 years, no N. americanus infection in age group 6 to 10 years (multivariable only), no Ancylostoma infection, no Giardia infection, no anaemia, female sex, socioeconomic quintile 5 (wealthiest)

Abbreviations: $R R$ relative risk, $A R R$ adjusted relative risk, $C l$ confidence interval, $P$, Wald test $P$-value

${ }^{* *} P<0.05,{ }^{* * *} P<0.01$ in univariable analysis

${ }^{a}$ The $N$. americanus main effect, being $N$. americanus infection intensity relative to no $N$. americanus infection in age group 1 to 5 years (reference age group)

${ }^{b}$ The age group 6 to 10 years main effect, being the relative risk of being aged 6 to 10 relative to being aged 1 to 5 when there is no $N$. americanus infection (reference group) ${ }^{c} N$. americanus infection intensity in age group 6 to 10 years is relative to no $N$. americanus infection in age group 6 to 10 years (because age group 6 to 10 years and moderate- or heavy-intensity $N$. americanus infection are not the reference groups)

${ }^{d} 10$ observations or less in subgroup; result should be interpreted cautiously

Normal weight is reference category, i.e. moderate and severe underweight need to be interpreted relative to this reference. Ascaris and $N$. americanus intensity infections defined according to following cut-points: Ascaris: heavy-intensity $C_{q} \leq 15.4$, moderate-intensity $C_{q}>15.4<31$, no infection $C_{q} \geq 31$; $N$. americanus: heavy-intensity $C_{q} \leq 24.6$, moderate-intensity $C_{q}>24.6<35$, no infection $C_{q} \geq 35$

adults or children. Interestingly, neither $N$. americanus nor Ascaris of either class of infection intensity were significant risk factors, this despite the well-recognised association between hookworm infection and blood loss. Whilst $N$. americanus is implicated in blood loss, it causes measurably less blood loss than Ancylostoma duodenale [10]. Blood loss due to parasite infection needs to be greater than nutritional reserves and required intake for anaemia to develop [35]. In this population the prevalence of the more pathogenic hookworm species Ancylostoma duodenale was very low, representing a possible explanation for the weak association between STH (particularly hookworm) and anaemia. Similar negligible associations have been identified in $N$. americanus-endemic populations elsewhere [35]. Socioeconomic status and age were not important risk factors for anaemia in adults, but were important, highly significant, risk factors for children. Different risk factor associations between children and adults point to the need to conduct further age-stratified analyses, ideally with children aged less than five analysed separately due to the higher prevalence of anaemia in this age group; observation numbers limited further agestratification in our analysis. Anaemia can be caused by multiple concurrent factors including inadequate dietary iron, and it is inherently difficult to control for all of these in epidemiological studies. The lack of other identified risk factors in our models would suggest that additional unmeasured factors may be influencing these results. Of note, the prevalence of malaria had dramatically declined in Timor-Leste prior to the commencement of this study [36], indicating that this is not a likely confounding factor.

In the study area, an extremely high prevalence of stunting, underweight and wasting in children were observed compared to the international reference population, with considerable proportions of severe stunting, underweight and wasting. These are higher than national estimates, possibly reflecting the rurality of the study communities. Our reported prevalence, whilst being at a district, not 
Table 10 Relative risk ratios for wasting, Manufahi District, Timor-Leste

\begin{tabular}{|c|c|c|c|c|c|c|c|c|c|c|}
\hline \multirow[b]{2}{*}{ Parameter } & \multicolumn{5}{|c|}{ Moderate wasting $(n=145)$} & \multicolumn{5}{|c|}{ Severe wasting $(n=44)$} \\
\hline & $\mathrm{RR}$ & $95 \% \mathrm{Cl}$ & ARR & $95 \% \mathrm{Cl}$ & $P$ & $\mathrm{RR}$ & $95 \% \mathrm{Cl}$ & ARR & $95 \% \mathrm{Cl}$ & $P$ \\
\hline Ascaris heavy-intensity & 0.83 & $0.42-1.6$ & 0.83 & $0.40-1.7$ & 0.4465 & $0.51^{\mathrm{a}}$ & $0.13-2.1$ & $0.37^{\mathrm{a}}$ & $0.07-1.9$ & 0.4942 \\
\hline Ascaris moderate-intensity & 0.73 & $0.38-1.4$ & 0.64 & $0.32-1.3$ & & $1.1^{\mathrm{a}}$ & $0.41-3.1$ & $0.92^{\mathrm{a}}$ & $0.32-2.7$ & \\
\hline N. americanus heavy-intensity & $1.7^{* *}$ & $1.1-2.8$ & 1.3 & $0.76-2.1$ & 0.5964 & $2.1^{* *}$ & $0.91-4.7$ & 1.2 & $0.51-3.0$ & 0.8431 \\
\hline N. americanus moderate-intensity & $0.87^{\mathrm{a}}$ & $0.35-2.1$ & $0.91^{\mathrm{a}}$ & $0.36-2.3$ & & $1.5^{\mathrm{a}}$ & $0.40-5.6$ & $1.4^{\mathrm{a}}$ & $0.35-5.4$ & \\
\hline Giardia infection & 0.79 & $0.47-1.3$ & & & & $0.46^{\mathrm{a}}$ & $0.17-1.2$ & & & \\
\hline Anaemia prevalence & 0.63 & $0.32-1.2$ & 0.83 & $0.41-1.7$ & 0.6140 & $0.66^{\mathrm{a}}$ & $0.22-2.0$ & $1.2^{\mathrm{a}}$ & $0.37-3.8$ & 0.7770 \\
\hline Male sex & 1.3 & $0.84-1.9$ & 1.2 & $0.79-1.9$ & 0.3580 & 1.3 & $0.68-2.7$ & 1.3 & $0.61-2.6$ & 0.5340 \\
\hline Age group 6 to 11 years & $3.0^{* * *}$ & $1.7-5.2$ & 2.9 & $1.6-5.1$ & $<0.0001$ & $3.5^{* *}$ & $1.3-9.3$ & 3.2 & $1.2-8.9$ & 0.0220 \\
\hline Age group 12 to 17 years & $4.9 * * *$ & $2.6-9.2$ & 4.3 & $2.2-8.4$ & $<0.0001$ & $7.8^{* * *}$ & $2.6-22.7$ & 7.1 & $2.3-21.8$ & 0.0010 \\
\hline Socioeconomic quintile 4 & 0.80 & $0.40-1.6$ & 0.82 & $0.39-1.7$ & 0.9181 & $0.89^{\mathrm{a}}$ & $0.27-3.0$ & $0.92^{\mathrm{a}}$ & $0.27-3.2$ & 0.8840 \\
\hline Socioeconomic quintile 3 & 0.72 & $0.35-1.5$ & 0.77 & $0.35-1.7$ & & $1.3^{\mathrm{a}}$ & $0.36-4.4$ & $1.3^{\mathrm{a}}$ & $0.35-4.6$ & \\
\hline Socioeconomic quintile 2 & 0.69 & $0.34-1.4$ & 0.79 & $0.37-1.7$ & & $0.60^{\mathrm{a}}$ & $0.16-2.3$ & $0.70^{\mathrm{a}}$ & $0.18-2.7$ & \\
\hline $\begin{array}{l}\text { Socioeconomic quintile } 1 \\
\text { (poorest) }\end{array}$ & 0.66 & $0.31-1.4$ & 0.68 & $0.30-1.5$ & & $0.59^{\mathrm{a}}$ & $0.15-2.3$ & $0.66^{\mathrm{a}}$ & $0.16-2.7$ & \\
\hline
\end{tabular}

Notes: Ascaris (categorical infection intensity), N. americanus (categorical infection intensity), Ancylostoma infection prevalence (binary), anaemia prevalence (binary), age group, sex and socioeconomic quintile were included in all multivariable regression models as exposure outcomes and covariates. Insufficient Ancylostoma spp. observations to investigate in this regression model. No interactions were significant in this model. Reference categories: No Ascaris infection, no N. americanus infection, no Ancylostoma infection, no Giardia infection, no anaemia, female sex, age group 1-5 years, socioeconomic quintile 5 (wealthiest) Abbreviations: $R R$ relative risk adjusted for age ${ }^{2}, A R R$ adjusted relative risk, $C l$ confidence interval; $P$, Wald test $P$-value

${ }^{* *} P<0.05$, ${ }^{* *} P<0.01$ in univariable analysis

${ }^{\text {a }}$ Ten observations or less in subgroup; result should be interpreted cautiously

Normal growth (no wasting) is reference category, i.e. moderate and severe wasting need to be interpreted relative to this reference. Ascaris and $N$. americanus intensity infections defined according to following cut-points: Ascaris: heavy-intensity $C_{q} \leq 15.4$, moderate-intensity $C_{q}>15.4<31$, no infection $C_{q} \geq 31$; $N$. americanus: heavy-intensity $C_{q} \leq 24.6$, moderate-intensity $C_{q}>24.6<35$, no infection $C_{q} \geq 35$

national level (and therefore perhaps more susceptible to small geographic area fluctuations), are amongst some of the highest reported rates in the world [37]. This is despite relatively low community prevalence of anaemia. Proportions of child wasting in particular are well above the 15\% level of severity classified as critical [38]. Wasting represents rapid and severe malnutrition such as starvation, although it can also be the result of chronic unfavourable conditions [38]. With strong links between wasting and child mortality [38] this level is considered to be a public health emergency [39] that requires immediate response. However, as a cautionary note, the application of the 2006 WHO international reference standards to the Timorese population has not been assessed, and there is a possibility of this population being of a smaller stature than the international standards, leading to overstated morbidity. Further investigations into applicability of these thresholds within Timor-Leste are required.

Stunting is often associated with poor nutrient availability in utero and the neonatal period from maternal breast milk, exacerbated by continuing poor nutrient supply during the period of introduction of solids [40]. It represents a period of chronic malnutrition during the most rapid growth period of life, leading to long-term and often permanent failure to attain linear growth. Wasting and stunting share direct and underlying causal factors, but it is not yet well understood how much wasting contributes to stunting and vice versa [41]. There are ongoing nutritional initiatives in Manufahi District including provision of food at schools. However, given the prevalence of wasting, stunting and underweight, there is an urgent need to further investigate nutrition in this community and enhance strategies to ensure that children are receiving adequate nutrition. The greater ARRs for severe stunting and wasting in older compared to younger children may reflect more food security for young children following the end of Indonesian occupation of Timor-Leste.

After controlling for socioeconomic status, sex, anaemia prevalence and age, there were few STH associations with child development indices, and most of the associations found fell short of the 5\% significance threshold. Of importance were the sex by $N$. americanus interaction for stunting, and the age group by $N$. americanus interaction for underweight: the interaction terms highlight complex interrelationships occurring in the population, and main effects of $N$. americanus intensity of infection in females were not significantly associated with morbidity. It should not be interpreted from this analysis that $N$. americanus infection is associated with reduced risk of either stunting or being underweight. There was no other indication of association between 
either N. americanus or Ascaris spp. infection intensities with stunting, underweight or wasting outcomes. The other significant helminth-associated finding was for an association of Ancylostoma infection with moderate and severe stunting, although trends were not in the expected direction, with Ancylostoma infection associated with reduced risk of severe stunting (Table 6). The prevalence of Ancylostoma in this population was low, at $4.7 \%$, leading to low numbers in regression models, and inability to categorise Ancylostoma into classes of infection intensity. Further, it was due to observed differences in the relationship between sex, age, $N$. americanus infection intensity, and stunting, that interactions were investigated. It could be that this underlying complex relationship also affected Ancylostoma. This finding of a 'protective' effect therefore needs to be interpreted cautiously.

The most significant risk factors for stunting and underweight were, generally, being male, and older child age groups, with additionally for stunting, being in the poorest socioeconomic quintile. Anaemia did not emerge as a risk factor for either stunting or underweight in this population. Underweight as a measure of child development is more variable than stunting, being influenced by both height and weight [38]. This may explain why poverty emerged as a risk factor for stunting but not being underweight in this population. Poverty could be a major contributing factor to chronic nutrient deprivation at critical rapid growth stages in this community. High stunting rates are usually indicative of poor socioeconomic conditions [38]; these rates may represent a legacy of conflict in this country. No risk factors were found for wasting with the exception of a greatly increased risk with older child age group for both moderate and severe wasting. These results, coupled with high STH prevalence, point to unmeasured risk factors in our study population, likely including nutritional risk factors, but also possibly genetic, behavioural and environmental risk factors.

Given high STH prevalence, the lack of other STH associations with morbidity in our models is surprising. However, this could be linked to the low level of anaemia and its negligible associations with child development outcomes in this population, given the most likely causal pathway between STH and morbidity is the role of hookworms contributing to blood loss and anaemia, with impacts on child development being more indirect. STH-morbidity associations have not been consistently found in studies of many different designs, contributing to a picture of complexity in understanding STH impacts on morbidity in populations that are often suffering multiple potentially interacting insults associated with poverty and deprivation (reviewed in [11]).

An alternative reason for the lack of STH associations with morbidity in our analysis may be that $N$. americanus morbidity may have been inadvertently overemphasised in studies that do not differentiate the hookworm genera (e.g. Necator and Ancylostoma). It could be that the burden of hookworm stems predominantly from Ancylostoma infection, and not $N$. americanus. This has been raised previously $[10,42]$. Further epidemiological studies investigating differential morbidity, using advanced diagnostic methods, are required.

Studies reporting morbidity associations with STH show varied results (reviewed in [11]). The lack of consistent associations between STH and morbidity outcomes, particularly child-related $z$-scores, is problematic for quantifying disease burden. Early estimates of the global burden of disease from STH had widely varying ranges, primarily based on the interpretation of morbidity in school-aged children [43]. Of particular importance is that, historically, it was the perceived importance of disease in school-aged children that became a crucial factor in international advocacy and development of mass school-based STH control programmes [43]. However a Cochrane systematic review has concluded that there is "substantial evidence that deworming does not improve average nutritional status or haemoglobin" [44], although this conclusion is disputed due to there being insufficient evidence in existence to confirm or refute the findings, despite research efforts [11]. Lack of evidence likely reflects the underlying heterogeneity of STH in different populations, alongside numerous potentially influencing factors such as community nutrition, poverty and comorbidities. This highlights the importance of continuing detailed investigations into morbidity associations, in an attempt to meet evidence shortfalls. New technologies such as qPCR will potentially play a very important role in generating this evidence.

Historically, it has been heavy-intensity of infection that has been considered by the WHO as contributing to greatest morbidity within the population, therefore in this analysis the decision was made to categorise between heavy- and moderate- rather than moderate- and lightintensity infections, so as to compare the heavy-morbidity category in the epidemiological analyses. Possibly, if the moderate and heavy-intensity infection categories were combined, to demonstrate a category of light-intensity infection, it could have affected the results in a population that was showing associations with heavy-intensity infection and morbidity, by 'hiding' covariate relationships. However, as no strong associations between heavyintensity STH and morbidity emerged, in this population the results may not have been affected substantially with a different categorisation of the intensity variable.

Population-based studies [27, 30-32, 45] are increasingly using PCR as a diagnostic tool for STH. However, using infection intensity has not been adequately 
undertaken to date. Of $\mathrm{C}_{\mathrm{q}}$ cut-points that have been assigned, only one prior investigation was found that specified how cut-points were allocated; this study also used dilution experiments from gene fragments for each species [30]. PCR data have therefore not yet been sufficiently validated using a wide range of infection intensities across populations, by contrast to categories of epg which are widely used for microscopy-derived measures of infection intensity despite their not very well acknowledged methodological weaknesses [42]. Based on Kato-Katz alone, our study population could be considered to have mainly 'light intensity' infections. This highlights an extremely important aspect of current STH diagnostics. Semi-quantitative PCR is considered to be more sensitive than Kato-Katz and thus traditional Kato-Katzbased classifications likely underestimate intensity of infection. For qPCR, sensitivity can be high enough to detect DNA from a single egg or L1 larva. Specificity of PCR-based tests is very high; offering a higher level of species-specificity. For example, Ancylostoma caninum (dog hookworm) has recently been detected in a significant proportion of human stool specimens collected in Tamil Nadu, India [46]. Using qPCR diagnostic tests, the definition of light-intensity infections from epg could now be called into question. In the absence of diagnostic 'gold standards' [29], and the increasing use of coprodiagnostic technologies, validating infection intensity using qPCR measures will become an increasingly important requirement. This analysis provides the first assignment of $\mathrm{C}_{\mathrm{q}}$ cut-points based on an algorithm correlating infection intensity as measured by $\mathrm{C}_{\mathrm{q}}$ value to an epg equivalent using the same faecal specimens. Major statistical inaccuracies can arise from setting datadriven cut-points [47], and this analysis should be seen as exploratory. Ideally further investigations of $\mathrm{C}_{\mathrm{q}}$-epg correlations are required. Further, population-based, and/ or mathematical modelling studies are required to derive $\mathrm{C}_{\mathrm{q}}$ cut-points that can be applied across populations.

\section{Limitations and strengths}

A limitation of this analysis is that there were insufficient observations to investigate anaemia risk factors in children under five, which was highly desired, or age-related differences for child development indices. Power calculations also indicated that there was power to detect risk factors for anaemia of odds ratios above 3.3, and for child morbidity relative risks of generally above 1.4. The prevalence was generally higher in young children; these are the most formative and highest-velocity growth years. Future research should investigate differential associations by age.

A further limitation of the study is that it was not possible to formally adjust for malaria prevalence. However, one of the largest recorded reductions in malaria incidence has recently been reported for Timor-Leste, with a $97 \%$ decrease in reported malaria incidence over 2006-2012 [36] to a very low level. This provides evidence for a low underlying incidence of malaria in these communities and hence this is believed to be a minor limitation. A final limitation of this study is, as it was a parasitological investigation, food intake assessment was not considered in the design. Important additional information could be provided by such an assessment in this population.

A major strength of this study is that it provides the first quantitative assessment of the role of STH on measures of morbidity in Timor-Leste, using advanced parasitological and epidemiological methods. This provides an important epidemiological evidence base to inform policy and programmatic planning. In particular, differentiation of $N$. americanus and Ancylostoma coupled with the low morbidity association overall, has enabled us to hypothesise that $N$. americanus morbidity effects have possibly been overstated in settings where less sensitive STH diagnostic tools have been used. This is a very important research priority to investigate further. Additionally, in conducting a parasitological survey, the need to investigate nutritional epidemiology in this district has been identified. Such investigations should commence as a priority.

\section{Conclusions}

This report provides the first assessment of STH associations with haemoglobin, stunting, wasting and underweight anthropometric measures in Timor-Leste. In this high-prevalence setting, only weak associations between STH of any species and developmental measures were found. Despite this, high prevalence of stunting, underweight and wasting in children illustrates the urgent need for investigating food quality and quantity in this community and providing nutritional enhancement, for example via micro- and macro-nutrient supplements. Additionally, regardless of the lack of association found between intensity of STH infection and morbidity in this study population, the high prevalence of STH provides a strong justification for introducing integrated STH control strategies. Deworming will reduce STH infections, but further nutritional interventions are going to be required to improve health.

\section{Additional file}

Additional file 1: Text 1. Investigation of qPCR data and subsequent categorisation into classes of Necator americanus and Ascaris spp. infection intensity. Figure S1. Necator americanus and Ascaris spp. intensity of infection ( $C_{q}$-value) distributions. Uninfected people were excluded from these figures for purposes of scale. Text 2 . Use of receiver-operating characteristic curves to statistically assign intensity of infection cut-points. Text 3. Use of epg- $C_{q}$ algorithm to statistically assign intensity of infection cut-points. Table S1 Ascaris 
spp. and Necator americanus intensity of infection quantification cycle $\left(\mathrm{C}_{q}\right)$ cutpoints between heavy and moderate morbidity assigned from receiveroperating characteristic curves. (DOCX $17 \mathrm{~kb}$ )

\section{Abbreviations}

AOR: Adjusted odds ratio; ARR: Adjusted relative risk; AUC: Area under ROC curve; BMI: Body mass index; BMIZ: BMI-for-age; Cl: Confidence interval; $C_{a}$ : Quantification cycle; DNA: Deoxyribonucleic acid; Epg: Eggs per gram of faeces; HAZ: Height-forage; OR: Odds ratio; $\mathrm{QPCR}$ : Quantitative real-time polymerase chain reaction; $\mathrm{RCT}$ : Randomised controlled trial; ROC: Receiver-operating characteristic curve; RR: Relative risk; SD: Standard deviation; STH: Soil-transmitted helminth; WASH: Water, sanitation and hygiene; WAZ: Weight-for-age; WHO: World Health Organization

\section{Acknowledgements}

We wish to thank the residents of Manufahi District who are kindly participating in our trial, the Timorese Ministry of Health for ongoing programmatic support, our WaterAid partners and the entire study team in Timor-Leste for their excellent and dedicated work. We thank Dr Jo-An Atkinson for instructive comments on an earlier draft of this manuscript

\section{Funding}

ACAC is an Australian National Health and Medical Research Council (NHMRC) Senior Research Fellow (1058878), JSM is an Australian NHMRC Practitioner Fellow, and DJG is an Australian NHMRC Career Development Fellow. This work is funded by an NHMRC Partnership project in collaboration with WaterAid Australia. The funders had no role in study design, data collection and analysis, decision to publish, or preparation of the manuscript.

\section{Availability of data and materials}

The datasets supporting the conclusions of this article are included within the article and its additional files. Raw data for the WASH for Worms trial will be made freely and publicly available at the completion of the trial and analysis of trial outcomes. This is anticipated at the end of 2016.

\section{Authors' contributions}

SJC and ACAC designed the analysis. SVN was responsible for data collection and entry. SVN and SJC conducted data cleaning and management. SL analysed qPCR specimens. SJC conducted data analysis, with statistical advice from CADE and ACAC. All authors have contributed suggestions to the analysis and played a role in interpreting findings. SJC wrote the manuscript, and all authors have contributed to writing, read and approved the final manuscript.

\section{Competing interests}

The authors declare that they have no competing interests.

\section{Consent for publication}

Not applicable.

\section{Ethics approval and consent to participate}

These analyses were conducted as part of a cluster randomised controlled trial (RCT) in Manufahi District, Timor-Leste (Australian and New Zealand Clinical Trials Registry ACTRN12614000680662). The study protocol was approved by the University of Queensland Human Research Ethics Committee; the Australian National University Human Ethics Committee; the Timorese Ministry of Health Research and Ethics Committee; and the University of Melbourne Human Research Ethics Committee. Participant informed consent processes involved explaining study purpose and methods, and obtaining signed consent from all adults and parents or guardians of children under 18 years of age, as described in [19].

\section{Publisher's Note}

Springer Nature remains neutral with regard to jurisdictional claims in published maps and institutional affiliations.

\section{Author details}

'Research School of Population Health, College of Medicine, Biology and Environment, The Australian National University, 62 Mills Rd, Acton, ACT 2601, Australia. ${ }^{2}$ Molecular Parasitology Laboratory, QIMR Berghofer Medical Research Institute, 300 Herston Rd, Brisbane, QLD 4006, Australia. ${ }^{3}$ School of
Public Health, University of Queensland, Herston Rd, Brisbane, QLD 4006, Australia. ${ }^{4}$ Clinical Tropical Medicine Laboratory, QIMR Berghofer Medical Research Institute, 300 Herston Rd, Brisbane, QLD 4006, Australia. ${ }^{5}$ Faculty of Veterinary and Agricultural Science, The University of Melbourne, Parkville, VIC 3010, Australia. ${ }^{6}$ Menzies School of Health Research, Charles Darwin University, Ellengowan Dr, Casuarina, NT 0810, Australia. ${ }^{7}$ Kirby Institute, University of New South Wales, Wallace Wurth Building, High St, Kensington, NSW 2052, Australia.

\section{Received: 23 July 2016 Accepted: 9 March 2017}

Published online: 19 April 2017

\section{References}

1. Hotez PJ, Ehrenberg JP. Escalating the global fight against neglected tropical diseases through interventions in the Asia Pacific region. Adv Parasitol. 2010;72:31-53.

2. UNDP. Human Development Report 2015. New York: United Nations Development Programme; 2015. [Accessed 15 December 2015]Available from: http://hdr.undp.org/sites/default/files/2015_human_development_report_0.pdf.

3. Martins N, McMinn P, Santina de Jesus Gomes M, Tomas Freitas L, Counahan M, Freitas C. Timor-Leste national parasite survey 2012 report \& recommendations. Dili: 2012

4. Campbell SJ, Nery SV, D'Este CA, Gray DJ, McCarthy JS, Traub RJ, et al. Water, sanitation and hygiene related risk factors for soil-transmitted helminth and Giardia duodenalis infections in rural communities in TimorLeste. Int J Parasitol. 2016:46:771-9.

5. Smith JL, Brooker S. Impact of hookworm infection and deworming on anaemia in non-pregnant populations: a systematic review. Trop Med Int Health. 2010;15(7):776-95.

6. Ahmed A, Al-Mekhlafi HM, Al-Adhroey AH, Ithoi I, Abdulsalam AM, Surin J. The nutritional impacts of soil-transmitted helminths infections among Orang Asli schoolchildren in rural Malaysia. Parasit Vectors. 2012;5:119.

7. LaBeaud AD, Nayakwadi Singer M, McKibben M, Mungai P, Muchiri EM, McKibben $E$, et al. Parasitism in children aged three years and under: relationship between infection and growth in rural coastal Kenya. PLoS Negl Trop Dis. 2015;9(5):e0003721.

8. Casapia M, Joseph SA, Nunez C, Rahme E, Gyorkos TW. Parasite risk factors for stunting in grade 5 students in a community of extreme poverty in Peru. Int J Parasitol. 2006;36(7):741-7.

9. Casapia M, Joseph SA, Nunez C, Rahme E, Gyorkos TW. Parasite and maternal risk factors for malnutrition in preschool-age children in Belen, Peru using the new WHO Child Growth Standards. Br J Nutr. 2007:98(6):1259-66.

10. Roche M, Layrisse M. The nature and causes of "hookworm anemia". Am J Trop Med Hyg. 1966;15(6):1029-102.

11. Campbell SJ, Nery S, Doi S, Gray DJ, Soares Magalhaes RJ, MCCarthy JS, et al. Complexities and perplexities: a critical appraisal of the evidence for soiltransmitted helminth infection-related morbidity. PLoS Negl Trop Dis. 2016; 10(5):e0004566

12. Bundy DA, Cooper ES. Trichuris and trichuriasis in humans. Adv Parasitol. 1989:28:107-73.

13. Crompton DW. Ascaris and ascariasis. Adv Parasitol. 2001;48:285-375.

14. WHO. The work of WHO in the South-East Asia region report of the Regional Director 1 January - 31 December 2014. New Delhi: 2015.

15. Agho KE, Dibley MJ, D'Este C, Gibberd R. Factors associated with haemoglobin concentration among Timor-Leste children aged 6-59 months. J Health Popul Nutr. 2008;26(2):200-9.

16. National Statistics Directorate (NSD) Timor-Leste, Ministry of Finance, Timor-Leste, ICF Macro. Timor-Leste demographic and health survey 2009-10. Dili: NSD, TimorLeste, and ICF Macro; 2010.

17. Lover AA, Hartman M, Chia KS, Heymann DL. Demographic and spatial predictors of anemia in women of reproductive age in Timor-Leste: implications for health program prioritization. PLoS One. 2014;9(3):e91252.

18. Llewellyn S, Inpankaew T, Nery S, Gray DJ, Verweij JJ, Clements ACA, et al. Application of a multiplex quantitative PCR method for assessing intestinal parasite infection in a prospective controlled interventional study in TimorLeste. PLoS Negl Trop Dis. 2016;10(1):e0004380.

19. Nery SV, McCarthy JS, Traub RJ, Andrews RA, Black J, Gray DJ, et al. WASH for WORMS: A cluster randomized controlled trial integrating a community-based water, sanitation and hygiene program with mass albendazole to reduce intestinal parasites in Timor-Leste. BMJ Open. 2015;5:e009293. 
20. Stoltzfus RJ, Dreyfuss ML, Chwaya HM, Albonico M. Hookworm control as a strategy to prevent iron deficiency. Nutr Rev. 1997;55(6):223-32.

21. WHO. Haemoglobin concentrations for the diagnosis of anaemia and assessment of severity Geneva: World Health Organization; 2011. Accessed 9 July 2015. Available from: http://www.who.int/vmnis/indicators/haemoglobin.pdf.

22. WHO. WHO Anthro (version 3.2.2, January 2011) and macros Geneva: World Health Organization; 2011. Accessed 3 Feb 2015. Available from: http:// www.who.int/childgrowth/software/en/.

23. WHO. WHO AnthroPlus software Geneva: World Health Organization; 2007. Accessed 3 Feb 2015. Available from: http://www.who.int/growthref/tools/en/.

24. De Onis M, Onyango AW, Borghi E, Siyam A, Nishida C, Siekmann J. Development of a WHO growth reference for school-aged children and adolescents. Bull World Health Organ. 2007;85(9):660-7.

25. WHO. Global reference list of 100 core health indicators. Geneva: World Health Organization; 2015. p. 2015.

26. Staudacher $O$, Heimer J, Steiner F, Kayonga Y, Havugimana JM, Ignatius R, et al. Soil-transmitted helminths in southern highland Rwanda: associated factors and effectiveness of school-based preventive chemotherapy. Trop Med Int Health. 2014;19(7):812-24.

27. Filmer D, Pritchett L. Estimating wealth effects without expenditure data or tears: an application to educational enrolment in states of India. Demography. 2001;38(1):115-32.

28. WHO. Helminth control in school-age children a guide for managers of control programmes. Geneva: World Health Organization; 2011.

29. Nikolay B, Brooker SJ, Pullan RL. Sensitivity of diagnostic tests for human soil-transmitted helminth infections: a meta-analysis in the absence of a true gold standard. Int J Parasitol. 2014;44(11):765-74.

30. Gordon CA, McManus DP, Acosta LP, Olveda RM, Williams GM, Ross AG, et al. Multiplex real-time PCR monitoring of intestinal helminths in humans reveals widespread polyparasitism in Northern Samar, the Philippines. Int $J$ Parasitol. 2015;45(7):477-83.

31. Jonker FA, Calis JC, Phiri K, Brienen EA, Khoffi H, Brabin BJ, et al. Real-time PCR demonstrates Ancylostoma duodenale is a key factor in the etiology of severe anemia and iron deficiency in Malawian pre-school children. PLoS Negl Trop Dis. 2012;6(3):e1555.

32. Wiria AE, Hamid F, Wammes $L$, Kaisar MM, May L, Prasetyani MA, et al. The effect of three-monthly albendazole treatment on malarial parasitemia and allergy: a household-based cluster-randomized, double-blind, placebocontrolled trial. PLoS One. 2013;8(3):e57899.

33. Brooker S, Bethony J, Hotez PJ. Human hookworm infection in the $21 \mathrm{st}$ century. Adv Parasitol. 2004;58:197-288.

34. WHO. Prevention and management of severe anaemia in pregnancy. Report of a Technical Working Group. Geneva: World Health Organization; 1993.

35. Brooker S, Jardim-Botelho A, Quinnell RJ, Geiger SM, Caldas IR, Fleming F, et al. Age-related changes in hookworm infection, anaemia and iron deficiency in an area of high Necator americanus hookworm transmission in south-eastern Brazil. Trans R Soc Trop Med Hyg. 2007;101(2):146-54.

36. Yapabandara MA, Sarmento R, de Fatima Mota Mdo R, don Bosco J, Martins $\mathrm{N}$, Wickremasinghe AR. Evidence-based malaria control in Timor Leste from 2006 to 2012. Malar J. 2015;14:109.

37. UNICEF/WHO/World Bank. Child malnutrition estimates September 2015 Geneva: UNICEF - WHO - World Bank Group; 2015. Accessed 23 Nov 2015. Available from: http://www.who.int/nutgrowthdb/estimates2014/en/.

38. De Onis M, Blossner M. WHO global database on child growth and malnutrition. Geneva: World Health Organization, 1997.

39. UNICEF/WHO/World Bank. Levels and trends in child malnutrition UNICEF WHO - World Bank Group joint child malnutrition estimates: key findings of the 2015 edition Geneva: UNICEF - WHO - World Bank Group; 2015. Accessed 23 Nov 2015. Available from: http://www.who.int/nutgrowthdb/ jme_brochure2015.pdf?ua=1.

40. WHO. Childhood stunting: challenges and opportunities report. Geneva: 2014 WHO/NMH/NHD/GRS/14.1.

41. WHO. Global nutrition targets 2025 wasting policy brief. Geneva: World Health Organization, 2015

42. Albonico M, Stoltzfus RJ, Savioli L, Tielsch JM, Chwaya HM, Ercole E, et al Epidemiological evidence for a differential effect of hookworm species, Ancylostoma duodenale or Necator americanus, on iron status of children. Int J Epidemiol. 1998;27(3):530-7.

43. Bethony J, Brooker S, Albonico M, Geiger SM, Loukas A, Diemert D, et al. Soil-transmitted helminth infections: ascariasis, trichuriasis, and hookworm. Lancet. 2006;367(9521):1521-32.
44. Taylor-Robinson DC, Maayan N, Soares-Weiser K, Donegan S, Garner P. Deworming drugs for soil-transmitted intestinal worms in children: effects on nutritional indicators, haemoglobin, and school performance. Cochrane Database Syst Rev. 2015;7:CD000371.

45. Easton AV, Oliveira RG, O'Connell EM, Kepha S, Mwandawiro CS, Njenga SM, et al. Multi-parallel qPCR provides increased sensitivity and diagnostic breadth for gastrointestinal parasites of humans: field-based inferences on the impact of mass deworming. Parasit Vectors. 2016;9(1):38.

46. George S, Levecke B, Kattula D, Velusamy V, Roy S, Geldhof P, et al. Molecular identification of hookworm isolates in humans, dogs and soil in a tribal area in Tamil Nadu, India. PLoS Negl Trop Dis. 2016;10(8):e0004891.

47. Royston $\mathrm{P}$, Ambler $\mathrm{G}$, Sauerbrei W. The use of fractional polynomials to model continuous risk variables in epidemiology. Int J Epidemiol. 1999;28(5):964-74.

\section{Submit your next manuscript to BioMed Central and we will help you at every step:}

- We accept pre-submission inquiries

- Our selector tool helps you to find the most relevant journal

- We provide round the clock customer support

- Convenient online submission

- Thorough peer review

- Inclusion in PubMed and all major indexing services

- Maximum visibility for your research

Submit your manuscript at www.biomedcentral.com/submit
C Biomed Central 